\title{
Large thoracic tumour without superior vena cava syndrome
}

\author{
N. Garmpis ${ }^{1 *}$, Ch. Damaskos ${ }^{1} 2^{2 *}$, N. Patelis ${ }^{3}$, D. Dimitroulis ${ }^{1}$, E. Spartalis ${ }^{2}$, I. Tomos ${ }^{4}$, \\ A. Garmpi ${ }^{5}$, M. Spartalis ${ }^{6}$, E.A. Antoniou' ${ }^{1}$, K. Kontzoglou' ${ }^{1}$, P. Tomos ${ }^{7}$ \\ ${ }^{1} 2^{\text {nd }}$ Department of Propaedeutic Surgery, Laiko General Hospital, Medical School, National and Kapodistrian \\ University of Athens, Greece \\ ${ }^{2}$ N.S. Christeas Laboratory of Experimental Surgery and Surgical Research, Medical School, National and Kapodistrian \\ University of Athens, Greece \\ ${ }^{3} 1^{\text {st }}$ Department of Surgery, Vascular Division, Medical School, National and Kapodistrian University of Athens, \\ Laiko General Hospital, Athens, Greece \\ ${ }^{4} 2^{\text {nd }}$ Pulmonary Department, Attikon University Hospital, Athens Medical School, National and Kapodistrian \\ University of Athens, Greece \\ 5Internal Medicine Department, Laiko General Hospital, University of Athens Medical School, Athens, Greece \\ ${ }^{6}$ Division of Cardiology, Onassis Cardiac Surgery Centre, Athens, Greece \\ ${ }^{7}$ Department of Thoracic Surgery, Attikon General Hospital, National and Kapodistrian University of Athens, \\ Medical School, Chaidari, Greece
}

[Received: 5 December 2016; Accepted: 3 February 2017]

\begin{abstract}
A 62-year-old male with long-standing smoking history presented with haemoptysis. Plain chest $X$-ray showed abnormal findings proximate to the right pulmonary hilum. Bronchoscopy revealed a fragile exophytic tumour of the right wall of the lower third of the trachea, infiltrating the right main bronchus (75\% stenosis) and the right upper lobar bronchus (near total occlusion). Contrast-enhanced chest computed tomography demonstrated a $7.2 \times 4.9 \mathrm{~cm}$ tumour contiguous to the above-mentioned structures, mediastinal lymph node pathology, and a vessel coursing inferiorly to the left of the aortic arch and anterior to the left hilum. Despite the tumour constricting the right superior vena cava (SVC), no signs of SVC syndrome were present. In this case, the patient does not present with SVC syndrome, as expected due to the constriction of the (right) SVC caused by the tumour, since head and neck veins drain through the persistent left superior vena cava (PLSVC). PLSVC is the most common thoracic venous anomaly with an incidence of $0.3 \%$ to $0.5 \%$ of the general population and it is a congenital anomaly caused by the failure of the left anterior cardinal vein to regress and to consequently form the ligament of Marshall during foetal development. It is associated with absence of the left brachiocephalic vein and in $10 \%$ to $20 \%$ of cases the right SVC is absent. Two potential draining points of the PLSVC have been previously reported. In the majority of cases PLSVC drains directly into the coronary sinus, but less frequently it drains into the left atrium or the left superior pulmonary vein (LSPV). In cases where the PLSVC drains into the coronary sinus, congenital heart defects are rare. The patient usually remains asymptomatic and PLSVC is an incidental finding during radiographic imaging or medical procedures. When the PLSVC drains into the left atrium or the $L S P V$, a right-to-left shunt is formed; a condition usually asymptomatic. In some reported cases this PLSVC variant presents with persistent, unexplained hypoxia or cyanosis and embolisation causing recurrent transient ischaemic attacks and/or cerebral abscesses. This PLSVC variant is more often associated with absence of the right SVC and congenital heart abnormalities. (Folia Morphol 2017; 76, 4: 748-751)
\end{abstract}

Key words: superior vena cava, thoracic, tumour, persistent left superior vena cava

Address for correspondence: N. Patelis, MD, MSc, PhD(c), First Department of Surgery, Vascular Division, Medical School, National and Kapodistrian University of Athens, Laiko General Hospital, Athens, Greece, e-mail: patelisn@gmail.com 


\section{INTRODUCTION}

Persistent left superior vena cava (PLSVC) is the most frequent congenital malformation of the thoracic venous system, as it affects $0.3-0.5 \%$ of the general population [2]. Approximately $4.5 \%$ of patients with a congenital heart disease (CHD) present with PLSVC $[2,15]$.

The term superior vena cava syndrome (SVCS) describes the various symptoms and signs of head and neck venous congestion, caused by obstruction of the superior vena cava (SVC) or innominate veins [19]. In $60 \%$ of all SVCS cases, the SVC is obstructed by a malignant tumour of the lung and mediastinum [13]. SVCS patients have a feeling of fullness in the head that is exacerbated when bending over or lying flat in bed. Other symptoms and physical signs might coexist and their severity depends on the degree of SVC stenosis.

In this case we present a patient with PLSVC, diagnosed incidentally during thoracic computed tomography (CT) for a tracheal tumour constricting the right SVC.

\section{CASE REPORT}

A 62-year-old male with long-standing smoking history presented with haemoptysis. His past medical history included atrial fibrillation under oral anticoagulants.

A plain chest $X$-ray showed abnormal findings proximate to the right pulmonary hilum. His anticoagulation prophylaxis was halted due to continuing haemoptysis and a diagnostic plan to undergo bronchoscopy.

Contrast-enhanced chest CT demonstrated a tumour adjacent to the right tracheal wall, the right main bronchus and the right upper lobar bronchus. The CT study also demonstrated an anomalous vessel coursing inferiorly to the left of the arch of the aorta and anterior to the left hilum (Figs. 1, 2).

Bronchoscopy revealed a fragile exophytic tumour, $7.2 \times 4.9 \mathrm{~cm}$ in size, adjacent to the right wall of the lower third of the trachea, also infiltrating the right main bronchus ( $75 \%$ stenosis) and the right upper lobar bronchus (near total occlusion; not letting the endoscopic fibre pass). Bronchoalveolar lavage material and bronchial secretions were collected for cytological analysis. No biopsies were collected due to the fragile nature of the tumour and its bleeding predisposal.

Despite the tumour constricting the right SVC, no signs of SVCS were present. The patient's only

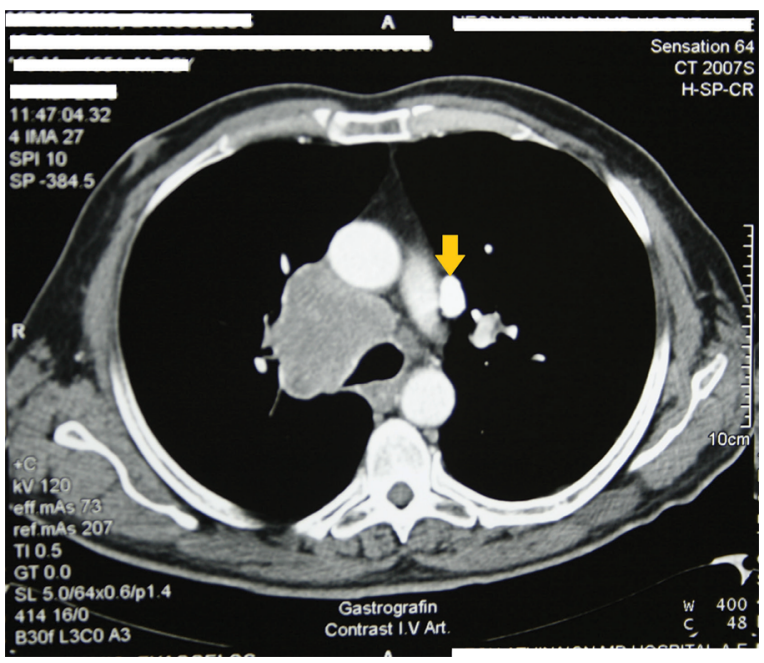

Figure 1. Transverse computed tomography cross section; arrow indicates left superior cava vein.

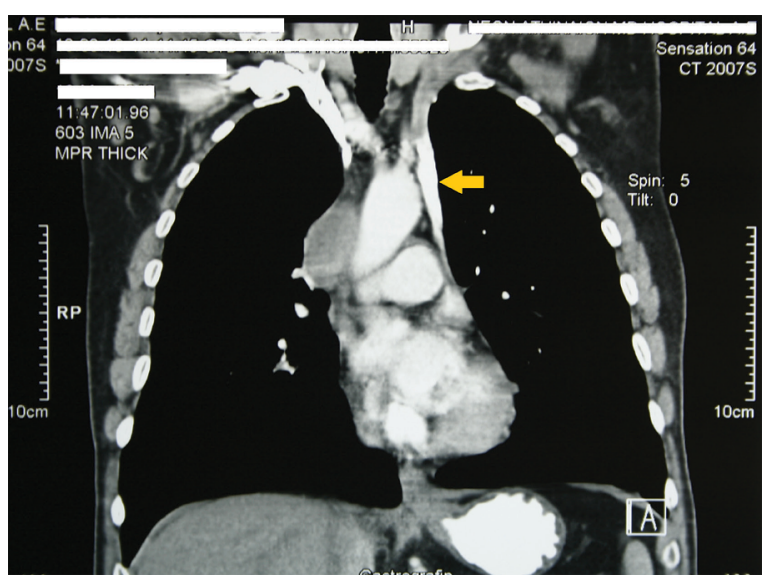

Figure 2. Coronal computed tomography cross section; arrow indicates left superior cava vein.

complaint continued to be haemoptysis and therefore his oral anticoagulation regime has to be altered.

The patient suffered a severe ischaemic stroke before any procedure was undertaken regarding his thoracic tumour and he passed 6 days later.

\section{DISCUSSION}

Persistent left superior vena cava affects $0.3-0.5 \%$ of the general population [2]. Cardiac malformations, such as atrial septal defect or tetralogy of Fallot, are present in approximately half of all patients with PLVSC [15]. In the majority of PLSVC patients, right SVC is present, but in $0.09-0.13 \%$ of patients with CHD, right SVC is absent and only PLVSC is 
present [17]. PLSVC is a persistent remnant of an early embryonic vessel, which could be described as a left SVC, and normally disappears as the embryo matures $[8,15]$. When detected in foetal life, PLSVC needs repeated follow-ups and constant inspection of the foetal anatomy, as it is frequently associated with heterotaxy syndromes and other malformations. Isolated PLSVC is a benign vascular anomaly and is usually asymptomatic and is detected when cardiovascular imaging is performed for unrelated reasons [5]. Diagnosis of PLSVC is relatively easy with contrastenhanced chest CT. Ventilation/perfusion scan could be of diagnostic value, only in cases where the PLSVC directly drains into the left atrium [12]. Plain chest $X$-ray can be misleading. Treatment is not necessary if $\mathrm{CHD}$ is not present and adequate left-to-right venous shunt exists.

Superior vena cava syndrome presents with a variety of symptoms, including dyspnoea on exertion, orthopnoea, headache, dizziness, syncope, or visual complaints and cough [19]. The most common complaint is a feeling of fullness in the head and neck, exacerbated when bending over or lying flat in bed. Physical signs of SVCS may include enlarged chest wall venous collaterals, facial and neck swelling, facial cyanosis, arm swelling and pleural effusion $[1,10,14,19]$. Although the majority of SVCS are caused by malignant tumours, thrombosis of the SVC secondary to central venous catheter or pacemaker placement could potentially be the cause $[9,13]$. Other causes are less frequent. CT angiography and magnetic-resonance venography (MRV) are both considered valuable methods in diagnosing SVCS. Ultrasonography of the jugular and the subclavian veins is an indirect noninvasive method to check SVC patency. Plain chest X-ray can set the diagnosis in the majority of cases, although this is based on indirect findings and a negative X-ray does not exclude SVCS as a diagnosis [10]. Contrastenhanced venography through simultaneous injection of contrast through the superficial veins of both the upper arms is the gold standard for setting the diagnosis of SVCS [18]. Treatment includes conservative measures, daily activity modification and anticoagulants. In cases of malignancy, chemotherapy, irradiation and combined chemoradiotherapy frequently improve patients' symptoms. Open surgical repair through a median sternotomy in SVCS cases caused by malignancy should be performed only if life expectancy exceeds 1 year $[3,4,7,11]$. Endovascular stenting of the SVC is an alternative that becomes widely available $[6,16]$.
Extra-anatomic bypass between the jugular and the femoral veins is an alternative if symptoms are severe and endovascular techniques fail or are not possible.

\section{CONCLUSIONS}

In our case, the right SVC is almost totally obstructed by the mediastinal tumour and the presence of PLSVC came to the patient's assistance, as no signs of SVCS developed. The PLSVC drained part of the head and neck blood flow back to the heart, thus decreasing the load to the right SVC. In this case, the therapeutic approach was to use the PLSVC as a temporary measure of symptom relief, until the mediastinal tumour was either excised or subjected to adjuvant conservative therapy depending on the tumours histology.

\section{REFERENCES}

1. Alimi YS, Gloviczki P, Vrtiska TJ, et al. Reconstruction of the superior vena cava: benefits of postoperative surveillance and secondary endovascular interventions. J Vasc Surg. 1998; 27(2): 287-99; 300, indexed in Pubmed: 9510283.

2. Buirski G, Jordan SC, Joffe HS, et al. Superior vena caval abnormalities: their occurrence rate, associated cardiac abnormalities and angiographic classification in a paediatric population with congenital heart disease. Clin Radiol. 1986; 37(2): 131-138, indexed in Pubmed: 3698495.

3. Chen KN, Xu SF, Gu ZD, et al. Surgical treatment of complex malignant anterior mediastinal tumors invading the superior vena cava. World J Surg. 2006; 30(2): 162-170, doi: 10.1007/s00268-005-0009-x, indexed in Pubmed: 16425072.

4. Dartevelle PG, Chapelier AR, Pastorino U, et al. Long-term follow-up after prosthetic replacement of the superior vena cava combined with resection of mediastinal-pulmonary malignant tumors. J Thorac Cardiovasc Surg. 1991; 102(2): 259-265, indexed in Pubmed: 1865699.

5. Galindo A, Gutiérrez-Larraya F, Escribano D, et al. Clinical significance of persistent left superior vena cava diagnosed in fetal life. Ultrasound Obstet Gynecol. 2007; 30(2): 152-161, doi: 10.1002/uog.4045, indexed in Pubmed: 17616965.

6. Gloviczki P, Pairolero PC, Cherry KJ, et al. Reconstruction of the vena cava and of its primary tributaries: a preliminary report. J Vasc Surg. 1990; 11(3): 373-381, indexed in Pubmed: 2313826.

7. Inoue $M$, Minami $M$, Shiono $H$, et al. Efficient clinical application of percutaneous cardiopulmonary support for perioperative management of a huge anterior mediastinal tumor. J Thorac Cardiovasc Surg. 2006; 131(3): 755-756, doi: 10.1016/j.jtcvs.2005.11.023, indexed in Pubmed: 16515944.

8. Kellman GM, Alpern MB, Sandler MA, et al. Computed tomography of vena caval anomalies with embryologic correlation. Radiographics. 1988; 8(3): 533-556, doi: 10.1148/radiographics.8.3.3380993, indexed in Pubmed: 3380993. 
9. Korkeila P, Nyman K, Ylitalo A, et al. Venous obstruction after pacemaker implantation. Pacing Clin Electrophysiol. 2007; 30(2): 199-206, doi: 10.1111/j.15408159.2007.00650.x, indexed in Pubmed: 17338716.

10. Laguna Del Estal P, Gazapo Navarro T, Murillas Angoitti J, et al. [Superior vena cava syndrome: a study based on 81 cases]. An Med Interna. 1998; 15(9): 470-475, indexed in Pubmed: 10079537.

11. Magnan PE, Thomas P, Giudicelli R, et al. Surgical reconstruction of the superior vena cava. Cardiovasc Surg. 1994; 2(5): 598-604, indexed in Pubmed: 7820520.

12. Pretorius PM, Gleeson FV. Case 74: right-sided superior vena cava draining into left atrium in a patient with persistent left-sided superior vena cava. Radiology. 2004; 232(3): 730-734, doi: 10.1148/radiol.2323021092, indexed in Pubmed: 15333794.

13. Rice TW, Rodriguez RM, Light RW. The superior vena cava syndrome: clinical characteristics and evolving etiology. Medicine (Baltimore). 2006; 85(1): 37-42, doi: 10.1097/01. md.0000198474.99876.f0, indexed in Pubmed: 16523051.

14. Rizvi $A Z$, Kalra $M$, Bjarnason $H$, et al. Benign superior vena cava syndrome: stenting is now the first line of treatment. J Vasc Surg. 2008; 47(2): 372-380, doi: 10.1016/j.jvs.2007.09.071, indexed in Pubmed: 18241760

15. Sarodia BD, Stoller JK. Persistent left superior vena cava: case report and literature review. Respir Care. 2000; 45(4): 411-416, indexed in Pubmed: 10780037.

16. Schindler N, Vogelzang RL. Superior vena cava syndrome. Experience with endovascular stents and surgical therapy. Surg Clin North Am. 1999; 79(3): 683-94, xi, indexed in Pubmed: 10410695.

17. Soward $A$, ten Cate F, Fioretti $P$, et al. An elusive persistent left superior vena cava draining into left atrium. Cardiology. 1986; 73(6): 368-371, indexed in Pubmed: 3791336

18. Stanford W, Doty DB. The role of venography and surgery in the management of patients with superior vena cava obstruction. Ann Thorac Surg. 1986; 41(2): 158-163, indexed in Pubmed: 3947168.

19. Wilson LD, Detterbeck FC, Yahalom J. Clinical practice. Superior vena cava syndrome with malignant causes. N Engl J Med. 2007; 356(18): 1862-1869, doi: 10.1056/ NEJMcp067190, indexed in Pubmed: 17476012. 